\title{
IMPORTANT NOTE ON SPAIN FOR THE GENERAL READER
}

I ASK READERS TO ACCEPT A PREMISE that is not fully fleshed out in the pages of this book: an incredible amount of linguistic and cultural diversity exists within Spain. The general English-speaking readers may not comprehend this diversity very well, not because they are willfully ignorant, but because Spain has been systematically portrayed as culturally uniform in the global imagination. To fully understand contemporary life in Spain-whether over the course of the last forty years or the past one hundred years-readers must be able to disentangle hegemonic from marginalized histories. One can go back even further, to debates over linguistic and cultural diversity that inform earlier time periods (e.g., modern, early modern, medieval ... ). The list of scholarly books written on these topics is extensive. Even so, the state of contemporary politics is prompting scholars to revisit and reformulate questions regarding historical visibility and representation. It is not expected that readers will have knowledge of these debates. Yet it is necessary, in this brief note, to provide a rudimentary baseline.

As recently as I3 October 2017, in the Madrid-based media outlet El País, the noted literary figure Antonio Muñoz Molina authored a brief article titled "En Francoland" (In Francoland). The piece was intended to call attention to continuing misperceptions of Spain and to some important general facts about its history. On I6 October 2017, El País published an English translation of that article titled "Foreign Perceptions of Spain: In Francoland."Therein, Muñoz Molina stresses that misperceptions abound. "Sometimes outside Spain," he writes, "one is forced to teach a history or geography lesson." It must be stated that this book on Pere Joan's comics is decidedly not a comprehensive cultural history of Spain. Nonetheless, I need to place my arguments about the comics artist's oeuvre in a general context. In that spirit, I offer a brief primer. 
Pere Joan is from the Balearic Islands, an autonomous community of Spain with its capital in the city of Palma de Mallorca. This autonomous community is bilingual- thus a basic introduction would state that Mallorcans speak both Spanish and Catalan. Both of these languages are also spoken in the autonomous community of Catalonia (of which Barcelona is the capital), the autonomous community of Valencia (of which Valencia is the capital), and the autonomous community of Aragon (of which Zaragoza is the capital). There are several autonomous communities in which Catalan is spoken-and they are very different from one another. Thus, I would prefer that readers of this book avoid two traps: that of thinking that Catalonia is the only region of Catalan language and culture, and likewise that of thinking that there are no important differences between and within these regions.

One can extend this premise to other languages, autonomous communities, and regions of Spain. Another example is the Basque language, which is spoken not only in the Basque Country (capital,Vitoria-Gasteiz), but also in Navarra (capital, Pamplona). Readers need to be aware that the Basque and Catalan languages are also spoken in some regions of France. The most comprehensive account of Spain's linguistic and cultural diversity would also note, for example, the existence of Galician and Asturian in northwest Spain. Moreover, these and other rudimentary notes on linguistic and cultural diversity are necessarily simplifications. The more closely one looks into a given autonomous community in Spain, the more internal heterogeneity one will find. Numerous discursive and political appropriations of linguistic and cultural identities must also be considered. That is, contemporary researchers are asking trenchant questions about how a variety of hegemonic, minoritized, and politicized group identities mobilize language and culture toward practical or strategic ends. Not least of all, along with these debates there is the existence of the Castilian language. More commonly referred to as "Spanish" by those outside Spain, Castilian has been deeply intertwined with a hegemonic cultural history. Minoritized constellations of language and culture have necessarily had to define themselves against the centralized governance structures historically associated with Castilian Spanish and notions of "Spanishness."

Muñoz Molina reminds readers of such issues in his brief piece published in El País. Outside of Spain, he argues, it is common to hear discussion of the country's "quaint backwardness" and its seeming lack of democratic ideals. As he makes clear, many people, including even 
professional journalists, are unaware that "the Basque Country is among the most advanced territories in Europe, with one of the highest standards of living, and that it has a degree of self-government and fiscal sovereignty considerably higher than any state or federal region in the world." Even those holding what he calls "educated opinions," a group that includes "academic and journalistic elites," nevertheless demonstrate a tendency to embrace "the worst stereotypes, particularly about the legacy of the dictatorship [of Francisco Franco]," which came to an end in 1975. Muñoz Molina goes further: "They feel insulted if we explain to them how much we have changed in the last 40 years: we don't attend Mass, women have an active presence in every social sphere, same-sex marriage was accepted with astonishing speed and ease, and we have integrated several million immigrants in just a few years, without outbursts of xenophobia." He also underscores that "the singularity of Catalonia was a priority for the new Spanish democracy" and that "the Generalitat, the Catalan regional government, was reestablished even before voting on the Constitution [of I978]," facts that have gotten lost in recent debates concerning the relationship between Catalonia and the Spanish state.

All this context is important. The way readers choose to see my exploration of Pere Joan's work may, in the end, depend on the set of perceptions they embrace. It is thus worth emphasizing a series of points that are implicit in my approach. I refrain from defining Pere Joan in limiting ways. It is unfair to categorize him solely as a Mallorcan artist, an artist from the Balearic Islands, a Catalan artist, an artist connected to the Barcelonabased comics industry, or a Spanish artist. He could perhaps be described in any of these ways-depending of course, on which argument is being made and why. My own opinion, however, is that these definitions are limiting for such an innovative and commanding comics creator and for an editor with such a clear international resonance and reputation.

This brief and admittedly rudimentary lesson on history and geography is merely the beginning of a long road when it comes to discussing Spain. Yet it is surely crucial for what follows. 
THIS PAGE INTENTIONALLY LEFT BLANK 
THE ART OF PERE JOAN 
THIS PAGE INTENTIONALLY LEFT BLANK 